
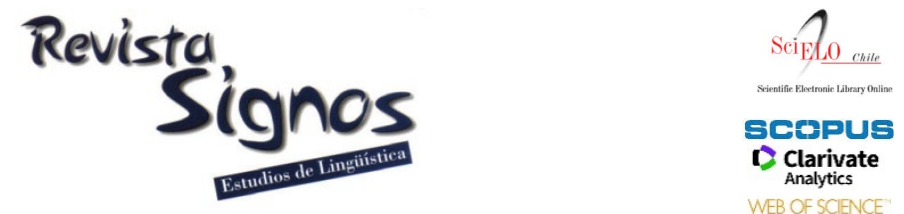

\title{
On the computational representation of constructions: The place of locative constructions in a knowledge base
}

\section{Acerca de la representación computacional de las construcciones: El lugar de las construcciones locativas en una base de conocimiento}

\author{
Carolina Rodríguez-Juárez \\ INSTITUTO UNIVERSITARIO DE ANÁLISIS Y APLICACIONES TEXTUALES \\ Universidad de Las Palmas de Gran CaNaria \\ ESPAÑA \\ carolina.rodriguez@ulpgc.es
}

Recibido: 09-III-2017 / Aceptado: 12-X-2018

DOI: $10.4067 /$ S0718-09342019000200357

\begin{abstract}
The aim of this paper is to further explore the formal representation of meaning as regards Level 1 (L1) or non-kernel constructions in the computational environment of the multipurpose lexico-conceptual knowledge base FunGramKB (Periñán-Pascual \& Arcas-Túnez, 2010, 2014) with special reference to L1-locative constructions in English. FunGramKB uses the parsing prototype ARTEMIS in order to automatically transduce fragments of natural language and generate their corresponding semantic representation under the format of a conceptual logical structure (CLS). Firstly, we aim to revise the criteria used in order to determine what factors can modify the argumental structure of kernel constructions (Fumero \& Díaz, 2017). Any deviation from the kernel construct attributed to a verbal predicate, whose grammatical and semantic information is stored in the Lexicon module of the knowledge base, will result in a particular type of L1-construction that has to be stored in the Grammaticon module, and that will have a direct impact on the formal representation of L1-constructions in ARTEMIS. Thus, the first part of the paper addresses the notion of construction in FunGramKB and revises the catalogue of L1-constructions proposed by Fumero and Díaz (2017). The second part focuses on the computational representation of the family of L1-locative constructions in English and shows how their idiosyncrasies should be formalized in the CLS so that they can be satisfactorily implemented in FunGramKB.
\end{abstract}

Key Words: ARTEMIS, conceptual logical structure, constructions, FunGramKB, locative constructions. 


\section{Resumen}

El objetivo de este artículo es avanzar en el análisis de la representación formal del significado en relación con las construcciones de nivel 1 o constructos no kernel en el marco computacional de la base de conocimiento léxico-conceptual y multipropósito denominada FunGramKB (Periñán-Pascual \& Arcas-Túnez, 2010, 2014), con especial referencia a las construcciones locativas en lengua inglesa. FunGramKB utiliza el prototipo de parseador ARTEMIS con el fin de transducir automáticamente fragmentos de lenguaje natural y generar su representación semántica bajo el formato de una estructura lógica conceptual. En primer lugar, nos proponemos revisar los criterios utilizados a la hora de determinar qué factores pueden modificar la estructura argumental de las construcciones kernel (Fumero \& Díaz, 2017). Cualquier desviación del constructo kernel de un predicado verbal, cuya información gramatical y semántica se encuentra almacenada en el módulo del Lexicón de la base de conocimiento, conllevará que este constructo sea reconocido como una construcción de nivel 1 específica que tiene que almacenarse en el módulo del Gramaticón y que tendrá un impacto directo en la representación formal de las construcciones de nivel 1 en ARTEMIS. La primera parte de este trabajo aborda la noción de construcción en FunGramKB y revisa el catálogo de construcciones de nivel 1 propuesto por Fumero y Díaz (2017). La segunda parte se centra en la representación computacional de la familia de construcciones locativas de nivel 1 y muestra cómo deben formalizarse las idiosincrasias de estas construcciones en la estructura lógica conceptual con el fin de que puedan implementarse satisfactoriamente en FunGramKB.

Palabras Clave: ARTEMIS, construcciones, construcciones locativas, estructura lógica conceptual, FunGramKB.

\section{INTRODUCTION}

Fortunately for linguists, and as recently claimed by Periñán-Pascual (2012, 2013) and Fumero and Díaz (2017) among others, for Natural Language Processing (NLP) systems to be able to permit natural language understanding, these systems need to be grounded in solid linguistic theories. The emergence of this trend and the growing interest in providing linguistically-oriented computational treatment of language should be perceived as a step forward in the integration and collaboration between linguists and computer engineers with the final aim of designing text processing applications that meet both the linguistic requirements and also the computation immediacy demanded in computation technology (Fumero \& Díaz, 2017). ${ }^{1}$

With this concern in mind, the multipurpose lexico-conceptual Functional Grammar Knowledge Base (FunGRamKB) for NLP (www.fungramkb.com) has been developed over the last few years (Periñán-Pascual \& Arcas-Túnez, 2004, 2007, 2010, 2014; Mairal \& Periñán-Pascual, 2009; Periñán-Pascual \& Mairal, 2009; PeriñánPascual, 2012, 2013). FunGramKB can be implemented in natural language understanding tasks with the aim of improving text-based systems such as machine translation, information retrieval or automatic summarizing, but also in order to 
develop dialogue-based applications such as question-answering or tutoring systems (Periñán-Pascual \& Arcas-Túnez, 2014).

FunGramKB is grounded on two robust and complementary linguistic models: (i) the projectionist model of Role and Reference Grammar (RRG) ${ }^{2}$ (Van Valin \& LaPolla, 1997; Van Valin, 2005), which provides the knowledge base with some basic assumptions related to the linking algorithm for the merging of lexical structures into constructional configurations (for example, Aktionsart ascription, macrorole assignment, status of variables, or logical structures, to name but a few); and (ii) the Lexical Constructional Model (LCM) (Mairal \& Ruiz de Mendoza-Ibáñez, 2008; Ruiz de Mendoza-Ibáñez \& Mairal, 2008; Ruiz de Mendoza-Ibáñez, 2013; Ruiz de Mendoza-Ibáñez \& Galera, 2014), which contributes to providing a layered structure of meaning construction that has helped to "fully integrate constructional meaning into RRG to deepen semantic processing” (Periñán-Pascual, 2013: 206). The LCM also offers a notion of construction that is more adequate for the computational requirements of the proof-of-concept computer application ARTEMIS (․utomatically Representing Text Meaning via an Interlingua-based System), a parsing device that incorporates RRG analytical tools and that FunGramKB exploits in order to automatically transduce fragments of natural language and generate their corresponding semantic representation under the format of a "conceptual logical structure" (henceforth CLS), which is, in fact, an improved representation of RRG logical structures (Periñán-Pascual \& Arcas-Túnez, 2014). ${ }^{3}$

This paper explores the notion of constructions in FunGramKB and revises the criteria that have been used in order to determine what factors can modify the internal configuration of the lexical templates of verbal predicates (Fumero \& Díaz, 2017). As such, a new criterion will be suggested and a revised version of the alphabetical catalogue of level 1 (L1) constructions by Fumero and Díaz (2017) will be presented. At a more specific level, the current research will strive to contribute to the analysis of the family of locative constructions in the English language by describing the peculiarities underlying each locative construction and how they can be formalised in the CLS so that the parser will be able to decode the syntactic behaviour of verbal predicates when analysed in terms of the parsing requirements of the syntactic rules of the Grammar Development Environment in ARTEMIS.

The remainder of this article is structured as follows. Section 1 presents a brief overview of the architecture of FunGramKB. Section 2 revises the notion of construction as it should be interpreted in a computational environment such as FunGramKB. Section 3 explores the criteria that define the factors that may have a direct impact on the argumental structure of kernel constructions and which will lead to a different L1-construction, and presents the revised version of Fumero and Díaz's (2017) FunGramKB alphabetical inventory of L1-constructions. Section 4 focuses on the family of constructions where the location argument shows an alternating 
behaviour and presents the different locative constructional schemas that are present in the revised catalogue, along with a detailed description of their FunGramKB grammatical and semantic representation. The concluding section summarises the main points previously discussed in this paper.

\section{A brief overview of FunGramKB}

The knowledge base FunGramKB is lexico-conceptual because it distinguishes three knowledge levels of analysis which consist of independent, but interrelated modules, as represented in Figure 1:

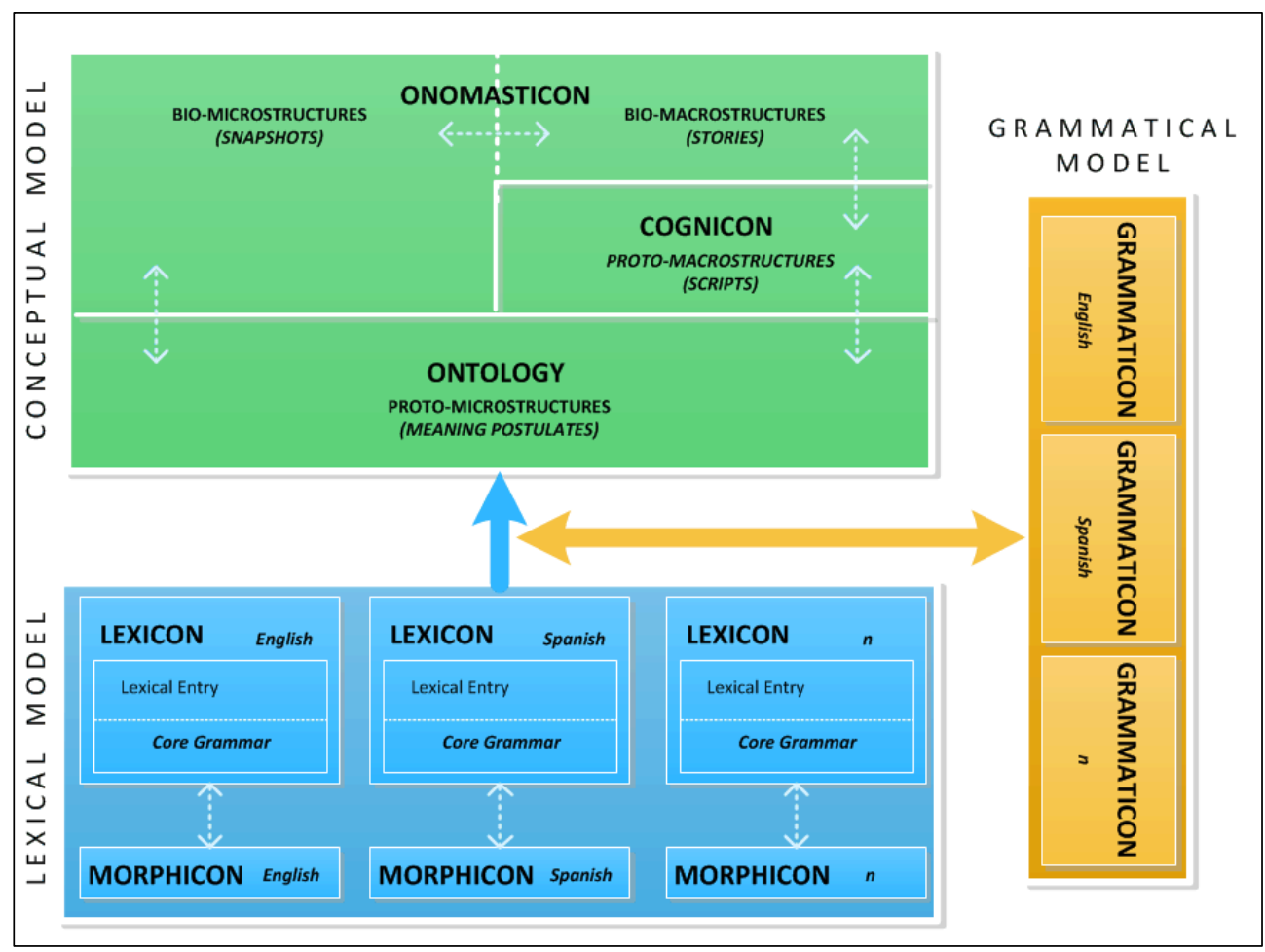

Figure 1. The FunGramKB architecture.

The conceptual module is language independent and includes encyclopaedic knowledge, procedural knowledge, and the central module in the system, the Ontology, which stores semantic knowledge in the form of conceptual units with their own distinguishing properties, i.e. a thematic frame and a meaning postulate (Mairal \& Periñán-Pascual, 2016). The grammatical module includes an inventory of constructional schemata stored in the Grammaticon and organised into four Constructicon modules that reflect the four different levels of constructional meaning in the LCM (argumental, implicational, illocutionary and discursive). Finally, the lexical module, apart from including basic (headword, index, language), morphosyntactic (graphical variant, abbreviations, phrase constituent, category, verb paradigm), and miscellaneous (dialect, style, domain, example and translation) information for each 
lexical entry in the Lexicon, incorporates a core grammar component in which we can find the attributes that are used by the system in the automatic building of the CLS of verbal predicates (see Table 1). These attributes are the Aktionsart of the verbal predicate, its lexical template (number of variables, macrorole assignment, the thematic frame mapping) and the potential set of constructions that a particular verbal predicate can be assigned to.

Table 1. Simplified representation of the attributes of spread in the Lexicon.

\begin{tabular}{|l|l|}
\hline \multicolumn{1}{|c|}{ Lexicon: } & \multicolumn{1}{c|}{ English } \\
\hline Concept: & +COVER_00 \\
\hline Aktionsart: & Causative accomplishment \\
\hline Variables: & $\mathrm{x}, \mathrm{y}, \mathrm{z}$ \\
\hline Macrorole: & $\mathrm{x}=$ Actor; $\mathrm{y}=$ Undergoer \\
\hline Thematic frame mapping: & $\mathrm{x}=$ Agent; $\mathrm{y}=$ Theme; $\mathrm{z}=$ Location \\
\hline Constructions: & $\begin{array}{l}\text { Locative construction, Middle construction (type 2), Middle } \\
\text { construction, Unexpressed third argument construction }\end{array}$ \\
\hline
\end{tabular}

In RRG, the macroroles Actor and Undergoer are conceived as generalizations of the different types of semantic roles and are associated with the two primary arguments of transitive and intransitive predications. They can be said to correspond to what has traditionally been called 'subject' and 'object' in syntactic terms. In transitive predications, Actor is the most agent-like argument (for instance 'you' in 'You can carry all your belongings in the bag') and Undergoer the most patient-like argument ('all your belongings' in the same example). In intransitive examples, and depending on the Aktionsart of the verb, the single argument of the predication can either be assigned the macrorole Actor in the case of activity verbs (e.g. 'run') or Undergoer in the case of state verbs (e.g. 'die'). ${ }^{4}$ As regards the arguments of the different thematic frames in FunGramKB, it should be noted that they are defined according to their metaconceptual distribution in each cognitive dimension. Thus, for instance, the thematic role Theme is defined as 'Entity that undergoes a cognitive process' if it belongs to the metaconcept \#COGNITION, as 'Entity that creates another entity' if it belongs to \#CREATION, or as 'Entity that changes its place or position' if it belongs to \#MOTION (http://www.fungramkb.com/resources/papers/tutorial2.pdf).

The verbs in the Lexicon are classified according to the number of variables in the lexical template into different 'kernel constructions', a term coined by Periñán-Pascual (2013) and Periñán-Pascual and Arcas-Túnez (2014) to refer to the basic types of constructions that every verbal predicate is provided with at the core grammar level, and which are built in terms of Aktionsart ascriptions and the corresponding lexical template. Thus, the number of variables in the lexical template will determine whether the verb will typically occur in a kernel-1 (intransitive), a kernel-2 (transitive) or a kernel-3 construction (ditransitive). In the Lexicon, each lexical entry, apart from 
having a basic kernel structure, also has pointers to the rest of the constructions that it may participate in (in the case of 'spread', for instance, there is a pointer to the locative construction, among others). These constructions are stored in the Grammaticon and are linked to the Lexicon by the lexical-grammatical interface.

In the parsing process of transforming language fragments into their equivalent semantic and grammatical structure, ARTEMIS will elaborate the constructional rules through the Grammar Development Environment by withdrawing information from the Lexicon and the Grammaticon, and this will result in the automatic generation of the CLS (Mairal \& Periñán-Pascual, 2016). The CLS constructor, which is one of the three components which conforms ARTEMIS (together with the COREL-Scheme Builder and the Grammar Development Environment), is an enriched and extended text meaning representation operating on the linguistic level that takes RRG logical structures as a basis and includes the following type of information: the Aktionsart ascription represented by operators such as CACC for causative accomplishment in the locative construction displayed in Figure 2 ('He spread her toast with butter'); the number of constructional variables of the predicate (for instance, $\mathrm{x}, \mathrm{w}, \mathrm{p}$ in the same example) together with information related to their Thematic Roles (Theme, Location, etc.); the assignment of macrorole functions (Actor/Undergoer); the type of phrase that each variable represents (adjective phrase, adverb phrase, noun phrase, etc.); syntactic information (whether the phrase is an argument, argument adjunct or a nucleus which contains the predicate); specification of the prepositions that are introduced by a particular predicate ('on' in the case of the predicate 'spread') and any other selectional preferences that should be made explicit by using basic concepts from the Ontology, such as +SURFACE_00 for the location argument, as illustrated in Figure 2, which shows the interface provided by the Grammaticon: 


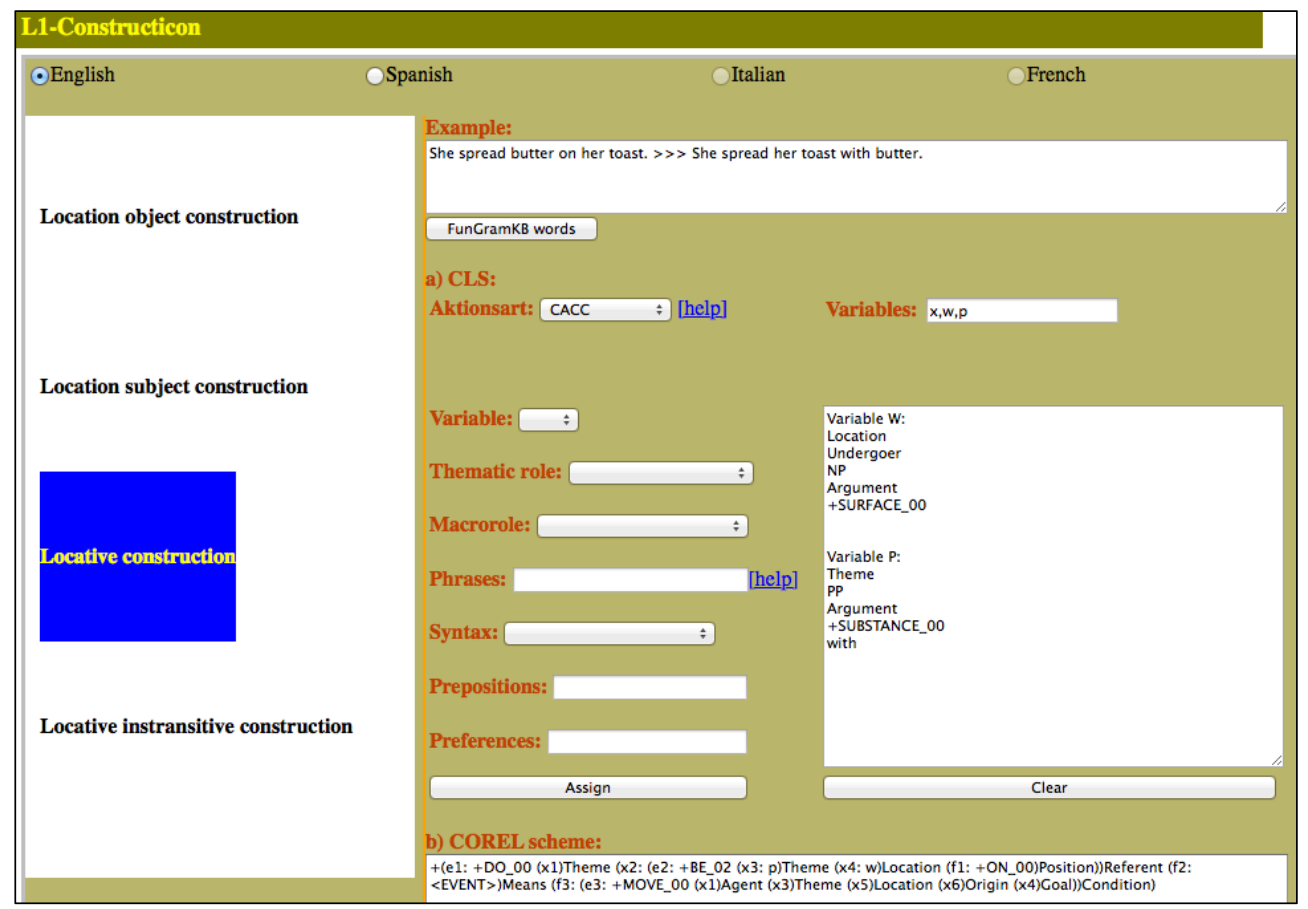

Figure 2. Interface of the L1-locative construction in the Grammaticon.

Here we show the CLS that is automatically generated for the predicate 'spread', and which includes FunGramKB ontologial concepts, an Aktionsart operator and a constructional operator (CONSTR-L1) that encodes constructional meaning:

$$
\begin{aligned}
& <_{\text {IF }} \text { DECL }<_{\text {TENSE }}{ }^{\text {PAST }}<{ }_{\text {CONSTR-L } 1} \text { KER } 3_{\text {AKT }} \text { CACC }<\text { [COVER_00 }(\% \text { SHE_00- } \\
& \text { Agent, +BUT'TER_00-Theme, +BREAD_00-Location)] }>>>>>
\end{aligned}
$$

In the last step in the parsing process, the CLS has to be automatically transduced into "a purely semantic conceptual representation in COREL" (Fumero \& Díaz, 2017: 37). COREL (Conceptual Representation Language) is the machine-readable metalanguage that is used in the conceptual semantic representation of CLSs "that serves as the input for the reasoning engine" (Van Valin \& Mairal 2014: 217), as shown below in the COREL scheme for the L1-locative construction that appears in the Grammaticon module in FunGramKB:

+(e1: +DO_00 (x1)Theme (x2: (e2: +BE_02 (x3: p)Theme (x4: w)Location (f1: +ON_00)Position))Referent (f2: <EVENT $>$ ) Means (f3: (e3: +MOVE_00 (x1)Agent (x3)Theme (x5)Location (x6)Origin (x4)Goal))Condition)

\section{On the notion of construction in FunGramKB}

Of the different modules that constitute FunGramKB, it is the Lexicon and the Grammaticon that we will be focusing on in this research study. We will be specifically 
revising one of the attributes in the core grammar component in the Lexicon which has to do with the inventory of argumental constructions in which verbs can take part: L1- constructions. ${ }^{5}$ The notion of construction, which is directly linked to the Grammaticon module (where constructional schemata are stored in different Constructicon modules), needs to be clearly and unequivocally defined in FunGramKB, as Periñán-Pascual himself highlights: "A key issue in this module [Grammaticon] is the definition of "construction"' (Periñán-Pascual, 2013: 213).

Periñán-Pascual (2013) points out that Goldberg's broad conception of construction in Construction Grammar ( $\mathrm{CxG}$ ) makes it difficult to provide an accurate definition of the term since from her point of view any single lexical item (or even a suffix such as -ed) could be conceived as a construction: "all levels of grammatical analysis involve constructions" (Goldberg, 2006: 5). This implies that, within this broad definition, constructions are conceived as the building blocks in linguistic realization. Periñán-Pascual's conception of construction differs from $\mathrm{CxG}$ and is closer to the LCM in the sense that constructions are viewed from a holistic perspective in which the meaning of the construction is always larger than the meaning of the building blocks conforming it. What is more, Periñan-Pascual (2013) shares Ruiz de Mendoza-Ibáñez's (2013) claim that for any linguistic pattern to be regarded as a construction some essential properties have to be met. Thus, the following criteria must be fulfilled by a form-meaning pairing for it to be regarded as a construction: in a construction, "form consists of a morphosyntactic arrangement of elements"; productivity, that is, the form-meaning pairing is productive if "it gives rise to a pattern whose formal part can be realized by predicates that obey the requirements of the meaning part of the pairing"; bi-univocity, that is, the relationship between form and meaning is bi-univocal in the sense that "form cues for meaning and meaning is realized by form"; and replicability, which accounts for the fact that a construction can be strictly invariably reproduced by other competent speakers with all its meaning implications in similar contexts (Ruiz de Mendoza-Ibáñez, 2013: 237).

In addition, Periñán-Pascual (2013) highlights that in the computational approach to constructional meaning a clear-cut distinction between 'construct' and 'construction' has to be established. Thus, constructs in FunGramKB, which, like constructions, are form-meaning pairings, are the building blocks that constitute a construction, and can take a different form depending on whether they are used in linguistic realization, in which case these minimal constructs adopt the form of lexical units, or in the language-independent conceptual representation of the semantics of a text (the COREL scheme), in which case they are represented by ontological concepts (Periñán-Pascual, 2013). He further argues that only some constructs can potentially be turned into constructions, which implies that a construction is necessarily a construct, but a construct cannot always be a construction. In fact, Periñán-Pascual (2013) distinguishes between 'constructional constructs' and 'non-constructional 
constructs', and advocates the use of the term 'construct' to refer to nonconstructional constructs, and restricts the term 'construction' to refer to those constructional constructs whose meaning is not derived from the individual constructs that make up the utterance. In a similar way, Luzondo-Oyón and Ruiz de MendozaIbáñez (2015) correctly address some theoretical issues regarding the notion of kernel constructions in FunGramKB that can contribute to a clearer distinction between what types of structures should be listed in the Lexicon and which ones stored in the Grammaticon. In this sense, they claim that it should be more appropriate to use the term 'kernel construct' for the structures that reside in the Lexicon and whose meaning is fully compositional (like, for instance, 'Bob kicked the ball'), and restrict the term 'construction' for those argument-structure constructions whose meaning is larger than the meaning of the building blocks conforming it, like 'John pounded the nail flat into the wall'. Similarly, Fumero and Díaz (2017) support this theoretical assumption and claim that the term 'kernel construct' should be restricted to those structures listed in the Lexicon, which would allow us to establish the difference with 'non-kernel constructions', which are "stored and described in the form of constructional schemata" (Fumero \& Díaz, 2017: 36) at the different levels of the Construction within the Grammaticon.

This way of using the term 'construction' in a computational environment should not be perceived as a challenge towards the widely spread and well supported notion of construction in other grammars, as Fumero and Díaz (2017) rightly highlight, but simply as a flexible view that tries to account for the fact that the information that is stored in the Grammaticon must comply with certain computational requirements imposed by the knowledge base itself such as the difference between kernel construct and construction, and the directionality of the morphosyntactic analysis, which will take for input the grammatical information stored in the Lexicon, and, in those cases in which that information turns out to be insufficient or conflictive with what the analysis is dealing with in the parsing process, it will have to turn to the Grammaticon where constructions are stored.

\section{Argumental constructions in FunGramKB: A computational perspective}

The English catalogue of constructions initially stored in the Grammaticon and listed in the Lexicon in FunGramKB was originally based on Levin's alternations (1993). However, the linguists working on these FunGramKB modules soon perceived that Levin's taxonomy of syntactic alternations was not adequate for the analysis of fragments of natural language in a computational environment, and that some adaptations were urgently needed so that the parsing rules in ARTEMIS could work satisfactorily. Luzondo-Oyón and Ruiz de Mendoza-Ibáñez (2015) have put forward two reasons to explain why Levin's alternations are not suitable within the FunGramKB knowledge base. On the one hand, they highlight the irrelevance of 
Levin's pairing of alternating structures, since the machine can only recognize and process the input text and identify it as an example of a particular construction, but does not have to process the different alternating possibilities of a particular verbal predicate. A second argument to support this view has to do with the fact that the closely related constructions that Levin pairs in her taxonomy are, in fact, perceived as distinct constructional schema in FunGramKB that may respond to differences in the number of variables or in the Aktionsart ascribed to the predicate in each construction (Luzondo-Oyón \& Ruiz de Mendoza-Ibáñez, 2015), and, as a result, be regarded as two distinct constructions (and not as a basic pattern along with a derived one).

By way of illustration, consider the term 'locative construction', which is often used as an umbrella term that subsumes different subtypes of structures. Levin's locative alternation (1993) includes the 'Spray/load alternation', the 'Clear alternation', the 'Swarm alternation' and the 'Wipe alternation'. Originally, and based on Levin's taxonomy, the locative construction was included in one of the four groups of alternations that are differentiated in the core grammar component in the Lexicon in FunGramKB, namely the group of 'Phrase shift' alternations in which it was presented as a single alternation without taking into account the different constructions that are subsumed under it.

As already mentioned, when the researchers in charge of completing the lexical entries for the verbal predicates started to fill in the syntactic information which was required in order to provide the knowledge base with all the relevant information for each lexical entry, different problems arose. In particular, the initial representation of the locative construction in FunGramKB was too narrow in the sense that all the possible variants of the locative construction were expected to be accounted for in terms of a single locative construction. This restricted view poses several problems due to the fact that, on the one hand, there is a long list of verbs involved in these constructions which are ascribed to different ontological domains, and on the other hand, each subtype needs to be accounted for taking into account idiosyncratic features related to macrorole assignment, addition or deletion of arguments, or specific selectional preferences, among others.

Bearing in mind the computationally-based notion of construction presented in Section 2 and the inadequacy of Levin's taxonomy for parsing, alternations have been substituted for constructional schemata, since the former are based on the modification of an input structural pattern and its derivation into a different one. However, the parser only recognizes the input text, in this case, a constructional pattern, so what the parser requires is:

"the actual description of each of the constructional patterns in which a verb can enter and a pointer in the Lexicon to lead the parser to the description of these constructions in the Grammaticon" (Fumero \& Díaz, 2017: 37). 
This section focuses on Level 1 constructions, which are stored at the argumental level (L1-Constructicon) in the Grammaticon in FunGramKB. L1-constructions modify the logical structure of the kernel construct in the core grammar and this is reflected in the CLS in ARTEMIS. Such a modification of the argumental structure can respond, as claimed by Fumero and Díaz (2017), to the following scenarios that specify whether the L1-construction has a direct impact on the number of arguments of the kernel construct, either by addition (as in 'Martha carved the piece of wood into a toy', where the creation and transformational construction adds a direct object ('the piece of wood') to the kernel construct ('Martha carved a toy'), and as a result the direct object is codified as an oblique argument in the L1-construction ('into a toy')), or by subtraction (like in the reciprocal object construction 'I confused Mary and Anna'); whether it involves a variation in Aktionsart ascription with respect to the verb class ascribed to the predicate in the kernel construct (as in the virtual reflexive construction 'This window just opens' (state)); and whether the construction implies both a variation in the number of arguments and also changes the Aktionsart (like in the resultative construction 'The pond froze solid' (addition, accomplishment)).

These criteria account for most of the instances of the L1-constructions included in the new FunGramKB inventory except for those cases in which the construction does not involve the addition or subtraction of arguments or a change in Aktionsart, but a shift of the phrases that does not affect transitivity and can only be accounted for as an instance of marked macrorole assignment. This is the case, for instance, of the locative construction with the verb 'spread', in which the kernel construct instantiates default macrorole assignment ('She (Actor) spread butter (Undergoer) on the bread'), whereas the L1-locative construction is an example of marked assignment to macrorole Undergoer ('She spread the bread (marked Undergoer) with butter'), in which there is no change in the number of arguments, nor in the type of Aktionsart ascribed to the verb. Therefore, we believe that a new criterion (d) should be incorporated to the list of criteria so far suggested in order to be able to account for the semantic and syntactic phenomena involved in each type of L1-constructions. Hence, we shall now present the enlarged set of criteria in the following list:

(a) The L1-construction subtracts arguments.

(b) The L1-construction adds non-optional constituents such as argument adjuncts or a secondary predicate.

(c) The L1-construction changes aspectual meaning, which implies that the construction introduces a new type of Aktionsart different from the type assigned to the kernel construct.

(d) The L1-construction involves phrase shift typically as a result of marked macrorole assignment.

(e) The L1-construction changes aspectual meaning (Aktionsart) and it also either adds or subtracts arguments, or involves phrase shift. 
By adopting these criteria, Fumero and Díaz (2017) have proposed an alphabetical catalogue of L1-constructions that has been arranged taking into account the requirements of the computational treatment and accounts for the incidence that these constructions have in the CLS found in the L1-construction module in ARTEMIS. Further to this, Appendix A presents my revised proposal of Fumero and Díaz's (2017) repertoire of L1-constructions in English, which differs from theirs in that the L1-constructions are not presented alphabetically but arranged into 5 sections that respond to the different criteria (a-e) operating in each case. Besides, each L1construction in the appendix has been provided with a representative example.

\section{Level 1 locative constructions in FunGramKB}

Having presented this fifty L1-construction catalogue (see Appendix A), the current section offers a detailed analysis of the locative constructional schemas that have been incorporated in the revised catalogue of English L1-constructions in FunGramKB. This proposal has been justified, as mentioned before, from a computational point of view in order to comply with the requirements of the knowledge base, but also from the grammatical point of view since it provides the grammatical and semantic representation for each of these L1-locative constructions, a type of information that has to be stored in the L1-Constructicon within the module of the Grammaticon in FunGramKB.

The analysis of the alternating behaviour of the location argument has led us to propose the following inventory of L1-constructions in FunGramKB (as shown in Table 2) that involve a change in the location argument taking into account the justifying criteria suggested so far:

Table 2. Inventory of L1-locative constructions in the Grammaticon (FunGramKB).

\begin{tabular}{|l|l|}
\hline \multicolumn{1}{|c|}{ CONSTRUCTION / Criteria } & \multicolumn{1}{c|}{ Kernel construct / L1-constructions } \\
\hline $\begin{array}{l}\text { 1. LOCATIVE } \\
\text { Criterion (d) }\end{array}$ & $\begin{array}{l}\text { She spread butter on her toast / } \\
\text { She spread her toast with butter. }\end{array}$ \\
\hline $\begin{array}{l}\text { 2. LOCATIVE INTRANSTIVE } \\
\text { Criterion (e) (Marked macrorole) }\end{array}$ & $\begin{array}{l}\text { Bees are swarming in the garden / } \\
\text { The garden is swarming with bees. }\end{array}$ \\
\hline 3. IMAGE IMPRESSION & $\begin{array}{l}\text { The jeweller inscribed the name (on the ring) / The } \\
\text { Criterion (b) }\end{array}$ \\
\hline $\begin{array}{l}\text { 4. LOCATION OBJECT } \\
\text { Criterion (e) (Phrase shift) }\end{array}$ & $\begin{array}{l}\text { The jeweller inscribed the name (on the ring)/ The } \\
\text { jeweller inscribed the ring. }\end{array}$ \\
\hline $\begin{array}{l}\text { 5. LOCATION SUBJECT } \\
\text { Criterion (e) (Subtraction) }\end{array}$ & $\begin{array}{l}\text { I carried } 5 \mathrm{~kg} \text { (in the backpack) / } \\
\text { The backpack carried } 5 \mathrm{~kg} .\end{array}$ \\
\hline
\end{tabular}

It is important to note that in these L1-constructions the location argument is encoded as a core argument and shows a phenomenon that has been coined as the 'holistic effect' (Anderson, 1971), which shows that the location entity is perceived as being completely or highly affected by the event described in the predication (in the 
case of 'spread', for instance, the toast is perceived as being fully covered by butter, a perception that is not produced in the kernel construct).

We will now move on to describe the type of semantic and syntactic information that has to be stored for each of these L1-locative constructions within the CLS in the Grammaticon in FunGramKB.

\subsection{Locative construction}

We have maintained the term 'locative construction' to exclusively refer to trivalent transitive constructions linked to putting verbs (such as the 'spray/load class') and also to some 'removing' verbs (such as 'clear', 'clean', 'drain' and 'empty'), as exemplified in the following kernel constructs (examples (1) and (3)) and L1-constructions (examples (2) and (4)): 6

(1) She spread butter on a deliciously aromatic roll. (BNC/JY3_W_fict_prose)

(2) Spread the cake with cream. (BNC/ABB_W_instructional)

(3) Babushka was (...) clearing snow from her path. (BNC/G23_W_pop_lore)

(4) ... while she cleared the bed of her things. (BNC/H94_W_fict_prose)

In the core grammar in the Lexicon, the kernel construct of these verbs is ascribed to the Aktionsart causative accomplishment, paraphrased as $\mathrm{x}$ CAUSES $\mathrm{y}$ and $\mathrm{z}$ to BECOME (NOT) be-Loc', where the variables are linked to the FunGramKB thematic roles of Agent, Theme and Location (as seen in Table 1). In the lexical entry, the number of macroroles has to be codified, as well as the variable that should be assigned to Undergoer. The location argument is codified as an oblique core argument introduced by various non-predicative locative prepositions depending on the verbal predicate in question ('on/over' in the case of the verb 'spread'; 'in/into' in the case of 'load', etc.), which have to be selected in the Lexical template II, where prepositions and collocations should be given.

The L1-locative construction, on the other hand, implies a shift in the position of the phrases in the construction, but does not entail a change in Aktionsart ascription, so we can claim that the criterion that can be applied to this type of construction is (d), which accounts for those L1-constructions that only involve a phrase shift typically as a result of marked macrorole assignment, as is the case here. Thus, in the CLS that has to be completed for this construction in the Grammaticon (see Figure 2), the slot for macrorole assignment must be filled in with the macrorole Undergoer for the variable assigned to the location argument, together with a selectional preference that indicates that it has to belong to the concept +SURFACE_00. Additionally, since the Theme presents a difference with respect to the information that is inherited from the Lexicon (in the kernel construct the Theme is a direct argument), here it has to be specified as an oblique core argument introduced by the preposition 'with' (in the case of 'putting' verbs, such as 'spray', 'load', etc.) or by the 
preposition 'of in the case of 'removing' verbs, as predicted by the RRG rule for prepositional marking which states that if the most-right potential argument in the logical structure is not selected as Undergoer, then it has to be marked by 'with' or 'of' according to the predicate (Van Valin, 2005). For an example of the automatic generation of the CLS and COREL scheme of this construction, see Section 1.

\subsection{Locative intransitive construction}

The locative intransitive construction is drastically different from the locative construction in that the verbs they contain are inherently intransitive verbs (monovalent) that appear with predicative locative prepositional phrases (adjuncts) which take as their argument the complete event which they participate in. The holistic construction changes the original Aktionsart into states in all cases, independently of the type of Aktionsart class ascribed to the three different verb classes participating in this L1-construction: states, as in example (5), semelfactives, as in (7), or activities, as in example (9). In all cases, however, the output Aktionsart of the construction will be 'state', as in (6), (8) and (10).

(5) $(\ldots)$ hearing your footsteps echo in the hollow cavern. (BNC/W_non_ac_soc_science)

(6) The whole forest was echoing with the snorts (...) of the awesome creature. (BNC/CH9_W_fict_prose)

(7) Ice crystals sparkle on her (...) crown. (BNC/CN1_W_misc)

(8) (...) a sky sparkling with brilliant stars. (BNC/W_fict_prose)

(9) Shoals of immature fish which swarm in the surface layers of the sea. (BNC/ CRJ_W_misc)

(10) The place was swarming with tortoises. (BNC/HA0_W_fict_prose)

The intransitive locative construction allows the locative argument (adjunct) to be the subject of the structure as a result of marked macrorole assignment following the Actor-Undergoer Macrorole Assignment Hierarchy (Van Valin, 2005). The fact that there is a case of marked macrorole assignment triggers the realization of the other non-selected potential macrorole argument (the original Theme) as a non-macrorole argument encoded as a 'with'-phrase. In Figure 3 below, you can see the CLS and the COREL scheme for this construction in FunGramKB: 


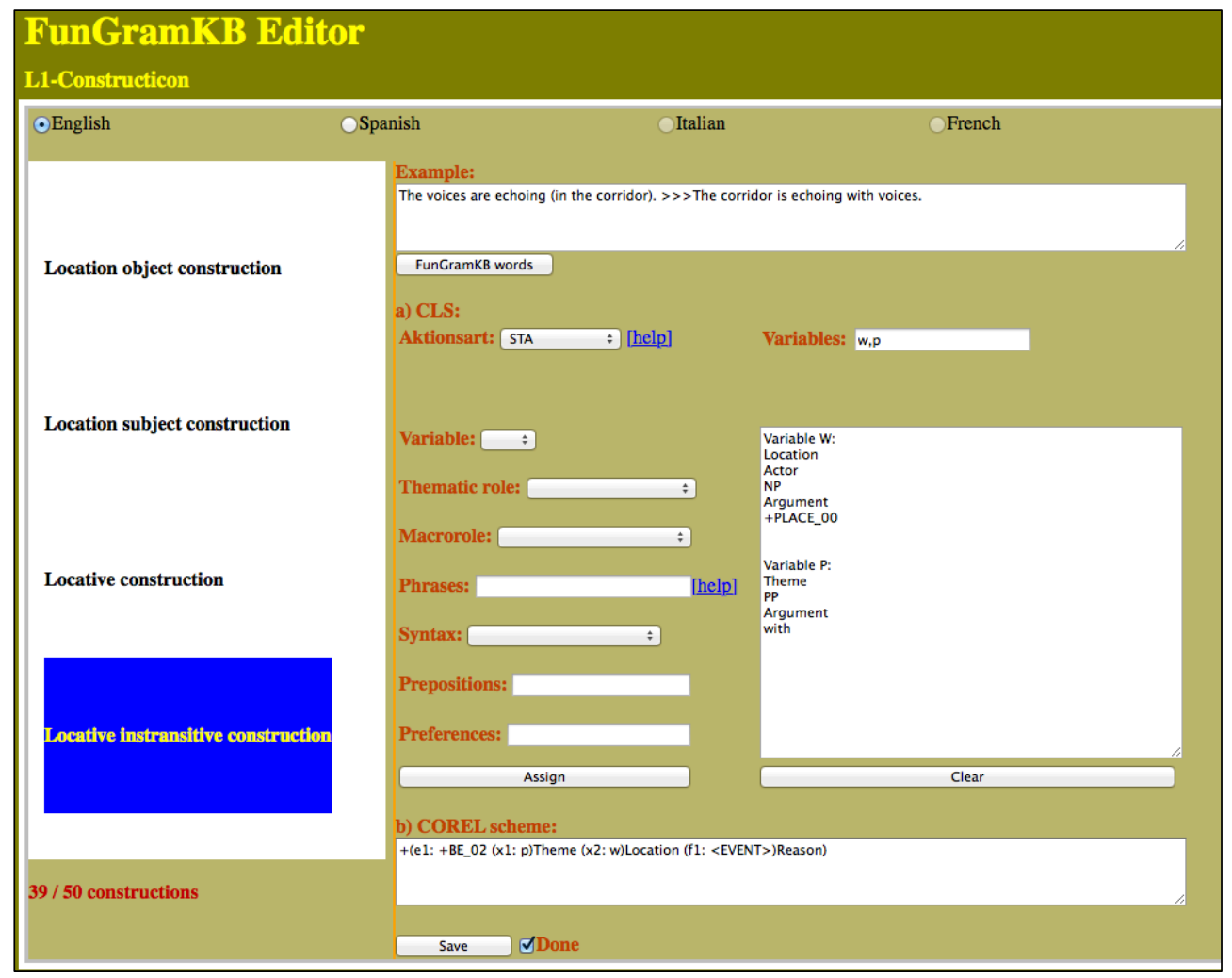

Figure 3. The L1-locative intransitive construction in the Grammaticon.

\subsection{Image impression construction}

The image impression construction might resemble 'putting' verbs in the locative construction since in both cases something is placed on a surface, but differs in the sense that with 'creation' verbs (e.g. 'engrave', 'imprint', 'tattoo', etc.), as a result of the event described by the verb, a new entity is created (i.e. a tattoo, an inscription, etc.). These verbs are ascribed to the Aktionsart active accomplishment, a type of event that is not changed by the construction. The kernel construct of these verbs in FunGramKB (exemplified in (11)) involves two arguments whose thematic roles, as explained in Section 1, are defined according to their metaconceptual distribution: a Theme, which in the metaconcept \#CREATION is defined as the entity that creates another ('members' in example (11)) and a Referent, conceived as the entity that is created by another entity ('their initials' in (11)). It is also common to find a prepositional phrase that should be analysed as an adjunct (an optional argument) encoding the location satellite from the meaning postulate of 'creation' verbs.

(11) Members queued to engrave their initials on the vast parchment. (BNC/ W_pop_lore)

(12) They would inscribe the shells with questions. (BNC/ W_fict_prose) 
The image impression construction, illustrated in (12), will upgrade the location adjunct by adding it to the construction as a core argument ('the shells') (criterion (b)) with a direct object function and an Undergoer value, which implies the shift of the status of the original core argument ('questions') that is now realised as an oblique 'with' prepositional phrase, signalling it as a possible (though unrealised) candidate for Undergoer status. Figure 4 shows the CLS and the COREL scheme for this construction:

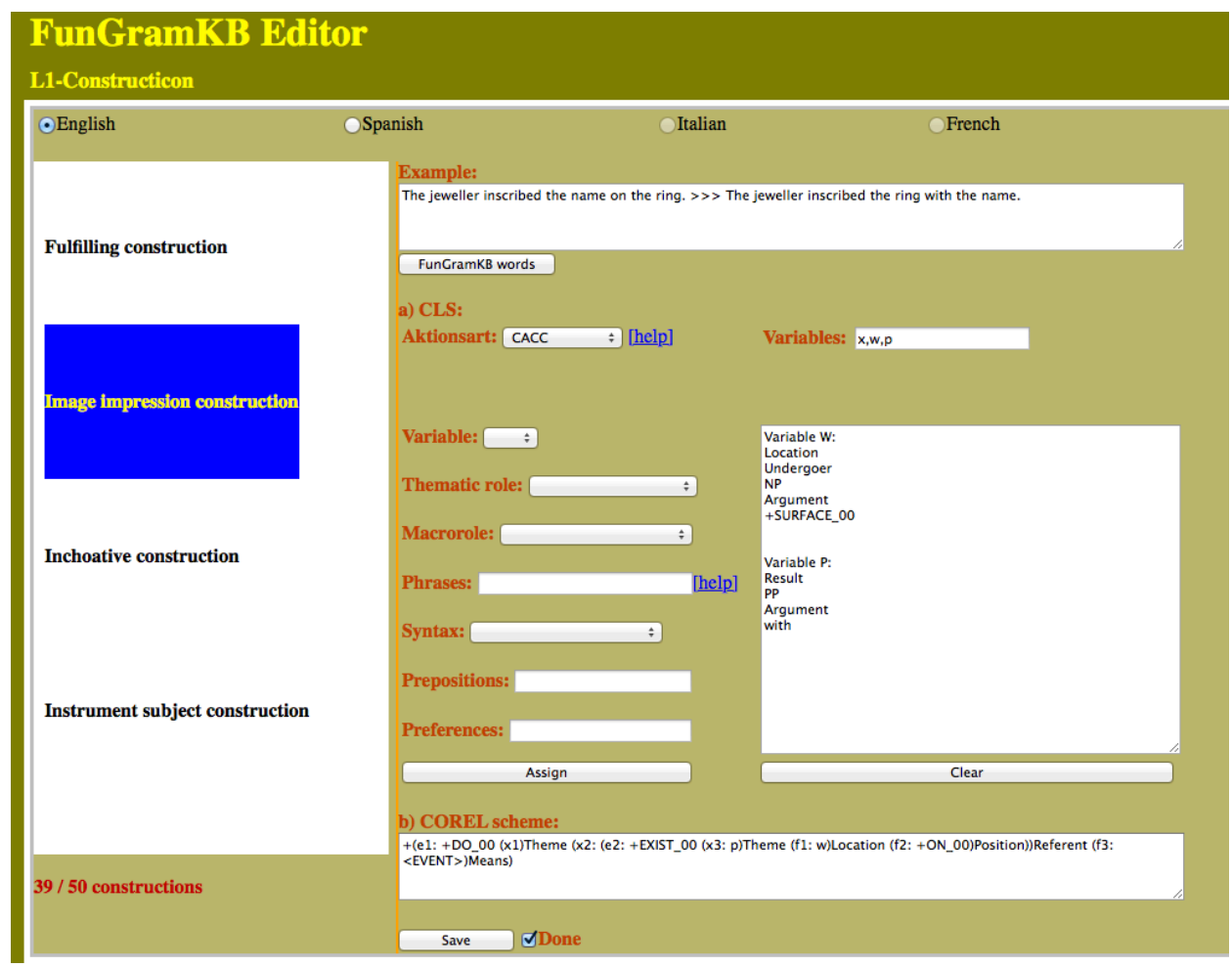

Figure 4. The image impression construction in the Grammaticon.

\subsection{Location object construction}

The location object construction exemplified in (14) is a new sub-type of locative construction, also linked to image impression verbs whose thematic frame, as was seen in the previous section, includes a Theme and a Referent. In this type of construction, the number of arguments remains the same in the L1-construction (i.e. two), but the big difference lies in the fact that the original Referent argument ('the name' in example (13)) in the kernel-2 construct is substituted (so it is deleted and a new argument is added) by a location argument which encodes the surface/location satellite ('her nose' in (14)) in the meaning postulate of these verbs, and which refers to the location (with the preferences +SURFACE_00, +SKIN_00) where the new created entity (images, writings, tattoos, etc.) is impressed, inscribed, tattooed, and so on. In other words, since in FunGramKB these verbs are codified as bivalent verbs 
with the thematic frame $x$-Theme and $y$-Referent, we have to find a way in which ARTEMIS can read these constructions. Thus, we need to indicate in the Grammaticon that within this construction there is a location satellite (argument) that has been promoted to argument status and that has been assigned the macrorole of Undergoer, implying the loss of the Referent argument (a potential Undergoer) which is unspecified in the construction.

(13) He (...) had tattooed the name in his right armpit. (BNC/ W_biography)

(14) Scarlet supposed she should be grateful that her daughter had not (...) tattooed her nose. (BNC/ W_fict_prose)

In terms of Aktionsart ascription, the location object construction implies a change with respect to the original Aktionsart of the kernel construct (active accomplishments) (criterion (e)), and represents a causative accomplishment in which $\mathrm{x}$ creates something that CAUSES that an unspecified but implicit entity BECOME be-on' a surface.

\subsection{Location subject construction}

The location subject construction is linked to what Levin (1993) calls 'fit' verbs ('carry', 'contain', 'fit', 'feed', 'hold', 'house', 'seat', 'serve', 'sleep', 'store', 'take', 'use'), which show the capacity of the location and allow the location to fill the slot of the subject. This L1-construction implies the loss of the first argument (criterion (a)) in the kernel construct (she in example (15)) and the promotion of a location/container adjunct to argument status codified as the subject in the construction in a parallel fashion to the upgrading of the location to object in the location object construction (Section 3.4).

(15) She was carrying the kitten in her mouth.

(BNC/ W_fict_prose)

(16) A large cafeteria seating over 300 people.

(BNC/ W_misc)

The location subject construction also involves a change of Aktionsart class, since 'fit' verbs in the kernel construct are causative states (where we have an activity predicate causing a state: $x$ does something that causes $y$ be in $z$ ), whereas the $L-1$ construction codifies states with two arguments: the first argument position ('a large cafeteria' in (16)) is a location argument whose capacity is specified by the second argument ('300 people' in (16)). In terms of macrorole assignment, and following the default Actor selection principle, the highest ranking argument in the logical structure must be assigned Actor (the participant responsible for the state of affairs, i.e. the logical subject), and the lowest ranking argument must be assigned Undergoer (the logical object in the state of affairs) following the Undergoer selection principle for default linking (Van Valin, 2005). 


\section{CONCLUSION}

This paper has focused on the constructions that are stored at the argumental level in the Grammaticon Module within the Functional Grammar Knowledge Base. We have shown how the notion of construction that is adopted in FunGramKB allows the machine to be able to clearly perceive a particular structure as a distinct constructional schema (e.g. 'The garden was swarming with bees') which differs from the kernel construct that is stored in the Lexicon and whose meaning is fully compositional (e.g. 'Bees are swarming in the garden'). We have discussed the criteria that justify the need to identify a particular structure as a distinct argumental construction and have proposed a further criterion that accounts for those L1constructions that involve phrase shift as a result of marked macrorole assignment. Thus, our proposal for including one further criterion to the ones that Fumero and Díaz (2017) suggest guarantees that all the changes introduced by the FunGramKB L1-constructions can be accounted for. In addition, our contribution to their proposal of a catalogue of L1-constructions pretends to improve the way that these constructions have been arranged and listed by adopting a linguistic approach, in which the FunGramKB L1-constructions have been classified and presented according to their linguistic behaviour and illustrated with representative examples, rather than adopting an alphabetical one.

We have also focused on the computational representation of the family of locative constructions in English and have provided a detailed description of the type of information that needs to be specified in each L1-locative construction in the Grammaticon so that the prototype ARTEMIS can automatically generate the CLS and COREL scheme for these constructions. This type of analysis has shown that both the Lexicon and the Grammaticon play a prominent role in the representation of locative constructions and has revealed that L1-locative constructions very often imply a change of Aktionsart, which may be accompanied by either the deletion or addition of one of the core arguments or by a phrase shift which responds to marked macrorole Undergoer assignment.

\section{REFERENCES}

Anderson, S. R. (1971). On the role of deep structure on semantic interpretation. Foundations of Language, 7, 387-396.

Barres, V. \& Lee, J. (2014). Template construction grammar: From visual scene description to language comprehension and agrammatism. Neuroinformatics, 12(1), 18-208. 
Bergen, B. K. \& Chang, N. (2005). Embodied construction grammar in simulationbased language understanding. In J. Östman \& M. Fried (Eds.), Construction grammars: Cognitive groundings and theoretical extensions (Constructional approaches to language 3) (pp. 147-190). Amsterdam: John Benjamins.

Boas, H. C. \& Sag, I. A. (Eds.) (2012). Sign-based Construction Grammar. Palo Alto Ca.: CSLI Publications.

Cortés-Rodríguez, F. \& Rodríguez-Juárez, C. (2018a). Parsing phrasal constituents in ASD-STE100 with ARTEMIS. Voprosy Kognitivnoy Lingvistiki, 3, 97-109.

Cortés-Rodríguez, F. \& Rodríguez-Juárez, C. (2018b). The syntactic parsing of ASDSTE100 adverbials in ARTEMIS. Paper presented at the $7_{\text {th }}$ International Conference on Meaning and Knowledge Representation, Institute of Technology Blanchardstown, Dublin, Germany.

Díaz, A. \& Martín, M. A. (2018). Computational treatment of clausal units in a controlled natural language: The ARTEMIS parser for ASD-STE100. Paper presented at the $36^{\text {th }}$ International Conference of the Spanish Association of Applied Linguistics, University of Cádiz, Spain.

Fumero, M. C. \& Díaz, A. (2017). The interaction of parsing rules and argumentpredicate constructions: Implications for the structure of the Grammaticon in FunGramKB. Revista de Lingüística y Lenguas Aplicadas, 12, 33-44.

Goldberg, A. E. (2006). Constructions at work: The nature of generalization in language. Oxford: Oxford University Press.

Levin, B. (1993). English verb classes and alternations. Chicago: University of Chicago Press.

Luzondo-Oyón, A. \& Ruiz de Mendoza-Ibáñez, F. J. (2015). Argument structure constructions in a Natural Language Processing environment. Language Sciences, 48, 70-89.

Mairal, R. (2017). A computational implementation of idiomatic and non-idiomatic constructions. Revista Signos. Estudios de Lingüistica, 50(94), 241-264.

Mairal, R. \& Periñán-Pascual, C. (2009). The anatomy of the lexicon component within the framework of a conceptual knowledge base. Revista Española de Lingüistica Aplicada, 22, 217-244.

Mairal, R. \& Periñán-Pascual, C. (2016). Representing constructional schemata in the FunGramKB Grammaticon. In J. Fleischhauer, A. Latrouite \& R. Osswald (Eds.), Explorations of the syntax-semantics interface (pp. 77-108). Düsseldorf: Düsseldorf University Press. 
Mairal, R. \& Ruiz de Mendoza-Ibáñez, F. J. (2008). Levels of description and explanation in meaning construction. In Ch. Butler \& J. Martín Arista (Eds.), Deconstructing Constructions (pp. 153-198). Amsterdam/ Philadelphia: John Benjamins.

Mairal, R., Guerrero, L. \& González, C. (Eds.) (2012). El funcionalismo en la teoría lingüistica. La Gramática del Papel y la Referencia. Introducción, avances y aplicaciones. Akal: Madrid.

Periñán-Pascual, C. (2012). En defensa del procesamiento del lenguaje natural fundamentado en la lingúistica teórica. Onomázęin, 26(2), 13-48.

Periñán-Pascual, C. (2013). Towards a model of constructional meaning for natural language understanding. In B. Nolan \& E. Diedrichsen (Eds.), Linking constructions into functional linguistics: The role of constructions in grammar (pp. 205230). Amsterdam: John Benjamins.

Periñán-Pascual, C. \& Arcas-Túnez, F. (2004). Meaning postulates in a lexicoconceptual knowledge base. Preceedings. 15th International Workshop on Databases and Expert Systems Applications, 38-42. Los Alamitos: IEEE.

Periñán-Pascual, C. \& Arcas-Túnez, F. (2007). Cognitive modules of an NLP knowledge base for language understanding. Procesamiento del Lenguaje Natural, 39, 197-204.

Periñán-Pascual, C. \& Arcas-Túnez, F. (2010). Ontological commitments in FunGramKB. Procesamiento del Lenguaje Natural, 44, 27-34.

Periñán-Pascual, C. \& Arcas-Túnez, F. (2014). The implementation of the FunGramKB CLS Constructor. In B. Nolan \& C. Periñán-Pascual (Eds.), Language processing and grammars: The role of functionally oriented computational models (pp. 165-196). Amsterdam: John Benjamins.

Periñán-Pascual, C. \& Mairal, R. (2009). Bringing role and reference grammar to natural language understanding. Procesamiento del Lenguaje Natural, 43, 265-273.

Rodríguez-Juárez, C. (2017). Accounting for the alternating behaviour of location argumnets from the perspective of role and reference Grammar. ATLANTIS. Journal of the Spanish Association of Anglo-American Studies, 39(2), 169-189.

Ruiz de Mendoza-Ibáñez, F. J. (2013). Meaning construction, meaning interpretation and formal expression in the Lexical Constructional Model. In B. Nolan \& E. Diedrichsen (Eds.), Linking constructions into functional linguistics: The role of constructions in grammar (pp. 231-270). Amsterdam: John Benjamins. 
Ruiz de Mendoza-Ibáñez, F. J. \& Galera, A. (2014). Cognitive modeling. A linguistic perspective. Amsterdam: John Benjamins.

Ruiz de Mendoza-Ibáñez, F. J. \& Mairal, R. (2008). Levels of description and constraining factors in meaning construction: An introduction to the Lexical Constructional Model. Folia Lingüistica, 42(2), 355-400.

Steels, L. (Ed.) (2011). Design patterns in fluid construction grammar. Amsterdam: John Benjamins.

Steels, L. (Ed.) (2017). Basics of Fluid Construction Grammar [on line]. Retrieved from: https://www.fcg-net.org/wp-content/uploads/papers/basics-of-fcg.pdf.

Van Valin, R. D. Jr (2005). Exploring the syntax-semantics interface. Cambridge: Cambridge University Press.

Van Valin, R. D. Jr \& LaPolla, R. J. (1997). Syntax, structure, meaning and function. Cambridge: Cambridge University Press.

Van Valin, R. D. Jr \& Mairal, R. (2014). Interfacing the Lexicon and an Ontology in a Linking Algorithm. In M. A. Gómez, F. Ruiz de Mendoza-Ibáñez \& F. Gonzálvez-García (Eds.), Theory and Practice in Functional-Cognitive Space (pp. 205-228). Amsterdam: John Benjamins.

\section{APPENDIX}

\section{Catalogue of L1-constructions in FunGramKB}

The revised catalogue of English L1-constructions in FunGramKB is presented in groups according to the criteria followed in order to regard a particular structure as a distinct L1-construction together, and with a representative example.

\section{Criterion (a). The L1-construction subtracts arguments}

1. Locatum Subject Construction ('Water filled the pail')

2. Reciprocal object Construction (trans.) ('I confused Maria and Anna')

3. Reciprocal Subject Construction ('Anne and Cathy met')

\section{Criterion (b). The L1-construction adds non-optional constituents}

1. 'As' Construction ('The president appointed Smith as press secretary')

2. Creation and Transformational Construction (transitive) ('Martha carved the piece of wood into a toy')

3. Image Impression Construction ('The jeweler inscribed the ring with the name')

4. Path PP Insertion Construction ('He climbed up the tree')

5. Reflexive Object Addition Construction ('He fixed the car himself') 


\section{Criterion (c). The L1-construction changes the type of Aktionsart of the kernel construct}

1. Causative Construction (accomplishment type) ('The heat decomposed the bodies')

2. Conative Construction (activity) ('He cut at the bread')

3. Conative Construction (semelfactive) ('Paula hit at the fence')

4. Locative Inversion Construction ('Home went Alice')

5. Split Subject Construction ('Meat fell in price')

6. Substance / Source Construction ('Heat radiates from the sun')

7. Virtual Reflexive Construction ('This window just opens itself')

\section{Criterion (d). The L1-construction involves a phrase shift (marked macrorole)}

1. Ditransitive Construction ('Bill sold Tom a car')

2. Locative Construction ('He spread her toast with butter')

3. Marked Undergoer Construction ('The judge presented the winner with a prize')

\section{Criterion (e). The L1-construction changes the Aktionsart and it also adds or subtracts arguments or involves phrase shift (marked macrorole assignment)}

\section{Addition}

1. Benefactive Object Construction ('Fido bought Jane a detective story')

2. Causative Construction (achievement type) ('Tony exploded the bomb')

3. Causative Motion Construction (atelic) ('The captain ran the soldiers around the camp')

4. Causative Motion Construction (telic) ('The captain ran the soldiers to the camp')

5. Caused-Motion Construction ('Peter sneezed the napkin off the table')

6. Cognate Object Construction ('Sarah sang a song')

7. 'For' Benefactive Construction ('Fido bought a detective story for Jane')

8. Fulfilling Construction ('I compensated the company with a six-month salary')

9. Intransitive Motion Construction ('He ran to the lake')

10. Measure Object Insertion (Creation and Consumption) Construction ('He drank a pint of beer')

11. Measure Object Insertion (Motion) Construction ('He ran the marathon')

12. Reaction Object Construction ('Pauline smiled her thanks')

13. Resultative Construction (intransitive accomplishments) ('The pond froze solid')

14. Resultative Construction (intransitive achievements) ('The window shattered into pieces')

15. Resultative Construction (non-subcategorized object) ('Anna swept the broom to pieces')

16. Resultative Construction (transitive accomplishments) ('Raid kills bugs dead')

17. Resultative Construction (transitive achievements) ('The kid popped the balloon into pieces')

18. Substance Addition Construction ('Oil was bleeding from the soil')

19. 'There'-Insertion Construction ('There darted into the room a little boy') 
20. Way Construction (motion) ('They pushed their way through the crowd')

21. Way Construction (resultative) ('They fought their way to freedom')

\section{Subtraction}

22. Container Subject Construction ('The paper incorporates the new results')

23. Inchoative Construction ('The window broke')

24. Instrument Subject Construction ('The hammer broke the window')

25. Location Subject Construction ('The backpack carried 5 kg')

26. Material Subject Construction ('That wheat flour bakes wonderful bread')

27. Middle Construction ('The bread cuts easily')

28. Middle Construction (2) ('This book doesn't sell')

29. Unexpressed Second Argument Construction ('He spent the evening reading')

30. Unexpressed Third Argument Construction ('They removed the dishes')

\section{Phrase shift}

31. Locative Intransitive Construction ('The corridor is echoing with voices')

Location Object Construction ('The jeweller inscribed the ring')

\section{NOTES}

${ }^{1}$ Steels (2017) revises the research programmes that have attempted to provide computational implementations that account for the way constructions are used in the parsing and production of utterances: Embodied Construction Grammar (Bergen \& Chang, 2005), Fluid Construction Grammar (Steels, 2011), Sign-based Construction Grammar (Boas \& Sag, 2012) and Template Construction Grammar (Barres \& Lee, 2014).

2 For a clear and rigorous introduction to the linguistic model of Role and Reference Grammar, see Mairal, Guerrero and Gonzalez (2012).

${ }^{3}$ For a recent study which stresses the role of linguists in text processing technologies and clearly details the steps which are followed in the syntax-semantics algorithm of the parsing procedure within ARTEMIS, see Fumero and Díaz (2017). Although the evaluation of ARTEMIS in natural language is still a pending issue, some advances have been made in the development of this proof-of-concept resource in order to measure, at least partially, its feasibility with respect to a Controlled Natural Language (CNL), namely ASD-STE100, the language used in the aerospace industry. So far, we have advanced in the development of the set of syntactic rules that are needed in order to account for the linear ordering of constituents such as clausal units (Díaz \& Martín, 2018), phrasal constituents (Cortés-Rodríguez \& Rodríguez-Juárez, 2018a) and adverbials (Cortés-Rodríguez \& Rodríguez-Juárez, 2018b) in this CNL. However, further development is still required for the effective parsing of ASD-STE100 prior to validating the ARTEMIS prototype in a natural language.

${ }^{4}$ For a detailed study of how to assign macroroles in constructions including a location argument within the framework of RRG following the macrorole selection principles presented in the Actor-Undergoer Hierarchy (Van Valin, 2005), see Rodríguez-Juárez (2017). 
5 For a recent paper on the formalization of constructions at different levels within FunGramKB, see Mairal (2017).

${ }^{6}$ All the examples used in this paper have been drawn from the British National Corpus (http://corpus.byu.edu/bnc/).

\section{ACKNOWLEDGMENTS}

* Financial support for this research has been received from the DGI, Spanish Ministry of Education and Science, project No. FFI2014-53788-C3-1-P. 